\title{
Varietal Performance of Radish (Raphanus sativus L.) Varieties in Black Soils of Vidharbha-Maharashtra, India
}

\author{
L.N. Dongarwar ${ }^{1 *}$, Sumedh R. Kashiwar ${ }^{2}$, S.M. Ghawade ${ }^{1}$ and Usha R. Dongarwar ${ }^{3}$ \\ ${ }^{1}$ Department of Horticulture, Dr. Panjabrao Deshmukh Krishi Vidyapeeth, Akola, \\ Maharashtra-444104, India \\ ${ }^{2}$ Dept. of Soil Science and Agricultural Chemistry, Palli Shiksha Bhavana, Visva-Bharati, \\ Sriniketan, West-Bengal-731236, India \\ ${ }^{3}$ Krishi Vigyan Kendra, Sakoli, Bhandara (ICAR, ZONE-V) Maharashtra-441802, India
}

*Corresponding author

\begin{tabular}{|l|}
\hline Key w or d s \\
Radish, Quality, \\
Pusa, Vidharbha \\
\hline Article Info \\
\hline $\begin{array}{l}\text { Accepted: } \\
\text { 06 December } 2017 \\
\text { Available Online: } \\
\text { 10 January } 2018\end{array}$ \\
\hline
\end{tabular}

\section{Introduction}

Radish (Raphanus sativus L.) belongs to genus Raphanus, family Brassicaceae or Cruciferae originated from the Central and Western China and India (Thamburaj and Singh, 2005). Vegetables are called as protective food as their consumption can
The present study was carried out at 'Chilli and Vegetable Research Unit', Dr. Panjabrao Deshmukh Krishi Vidyapeeth, Akola, Maharashtra during winter season of 2013-14 to investigate growth, yield and qualitative parameters of various radish varieties. The experiment was laid out in Randomized Block Design (R.B.D.) with seven treatments and three replicatations. Seven varieties of radish, used for the study as treatments were viz., PusaDesi, PusaHimani, PusaReshmi, PusaChetaki, ArkaNishant, Japanese White, IHR-11. The growth parameters like plant height was maximum at $28.29 \mathrm{~cm}$ in ArkaNishant, while it was minimum at $22.70 \mathrm{~cm}$ in PusaHimani, also the chlorophyll content of leaves was $3.10 \mathrm{mg} \mathrm{g}^{-1}$ recorded in ArkaNishant. However, the minimum leaf area was $85.04 \mathrm{~cm}^{2}$ recorded in PusaHimani and minimum chlorophyll content of leaves was $1.61 \mathrm{mg} \mathrm{g}^{-1}$ in variety PusaDesi. The substantial variations in weight of total fresh weight of plant (190.06 $\mathrm{g}$ to $226.60 \mathrm{~g}$ ) were observed. It was maximum in variety ArkaNishant, whereas, minimum in variety PusaDesi. The values of root diameter were minimum in IHR $-1-1(2.60 \mathrm{~cm})$ and maximum $(3.69 \mathrm{~cm})$ in variety ArkaNishant. The maximum root yield per plot was 32.34 $\mathrm{kg}$ plot $^{-1}$ produced in variety ArkaNishant. The maximum moisture content of root (97.75\%) was recorded in ArkaNishant variety. Whereas, it was found minimum (95.35\%) in the variety IHR-1-1. The maximum crude fiber content of root was $1.71 \%$ in variety IHR-1-1 and minimum content recorded in the variety ArkaNishant was $1.32 \%$. prevent several diseases. Vegetables are the richest and cheapest source of natural protective food contributing carbohydrates, proteins, fats, vitamins and minerals. The vegetable consumption as per the recommended of the dietitians should be $300 \mathrm{~g}$ per day per capita and its availability is $145 \mathrm{~g}$ in India. Out of $300 \mathrm{~g}$ of vegetables, $125 \mathrm{~g}$ of 
green leafy vegetables, $100 \mathrm{~g}$ of roots and $75 \mathrm{~g}$ of other vegetables (Salaria, 2009).India is the second largest producer of vegetables after China. The total area under vegetables in India is 8.98 million ha with 156.32 million tonnes of annual production and average productivity level is 17.4 tonnes $\mathrm{ha}^{-1}$. An area under vegetables in Maharashtra is 6.11 lakh hectares with 75.04 lakh tonnes of annual production with average productivity 12.3 tonnes $\mathrm{ha}^{-1}$ (NHB, 2012). Vegetables are mainly grown in West Bengal, Bihar, Uttar Pradesh, Karnataka, Punjab, Maharashtra and Assam. In Maharashtra, vegetables are grown on large scale throughout the year in areas around the big cities.

Radish is grown for its young tender tuberous roots which are eaten raw as a salad or cooked as a vegetable. It is relished for its pungent flavor and is considered as an appetizer. The young leaves are also cooked as vegetable and eaten. Radish has refreshing and depurative properties. Radish is useful in liver and gall bladder troubles. In homoeopathy, they are used for neuralgic headache, sleeplessness and chronic diarrhea. Roots, leaves, flower and pod are quite effective against gram positive bacteria. The roots are said to be useful in urinary complaints, piles and in gastrodynia. A salt extracted from roots, dried and burnt to white ash is said to be used as diuretic and laxative.

The seeds are said to be pectin, expectorant, diuretic and carminative (Kirtikar and Basu, 1935). Radish is an annual or biannial herb depending on root or seed production. The rosette leaves are lyratepinnatified and may vary from $10-15 \mathrm{~cm}$ in small rooted cultivars to much as $30 \mathrm{~cm}$ long leaves are usually covers with stiff bistles. The inflorescence of radish is typical terminal raceme of cruciferae. The flowers are small, white, rise or liliac in colour with purple veins in bractless racemose, sepals, erect petals clawed. The shape varies from oblate to long tapering and exterior colour varies from white various shades of scarlet. Some of red cultivars are white tipped. However, the flesh colour of all cultivars is white. The edible part of radish is tap root. The edible portion of radish root develops from both primary root and hypocotyls. The primary root and hypocotyls develop into edible portion of radish root. Radish roots vary greatly in size, shape and other external characters as well as for the time upto which they remain edible. Depending upon cultivar, the length may vary from $25-30 \mathrm{~cm}$.

Shape from cylindrical to long tapering and the external colour may be white or different shades of scarlet with various flesh colored variety have also been developed. The new trend in vegetable production is not only to obtain higher yields but also to have better quality produce, as producers are getting higher price for quality produce. There are several factors like variety, season of planting, nutrition and irrigation which plays a dominant role in yield contribution and quality production.

Among these factors variety is a predominant. Several varieties of radish are available in the market having varying length, size, colour, taste, yield potential and quality parameters. The varieties like PusaDesi, PusaChetki, PusaReshmi, PusaHimani, Japanese White, ArkaNishant, and IHR-1-1 are grown in different parts of the state. Higher yield, long sized roots and earliness are some of the characters which might be responsible for increase in the profit of radish growing farmers. In recent years, due to increased urbanization and change in food habits, the demand for salad vegetables is increasing very rapidly. The consumers as well as growers are demanding for the varieties having good qualities. As radish is an important salad vegetable, it is in demand throughout the year 
in big cities. The vegetables from this region are also sold in the big markets like Mumbai, Pune, Nagpur and Hyderabad. One of the most important reasons for low production of the radish in farmer's field is lack of knowledge on suitable varieties (Gautam and Khatiwada, 1997). The information regarding the radish varieties suitable for Vidharbha region is scanty. Farmers are asking for high yielding varieties with good quality of roots.

The growth, yield and quality performance of the radish varieties varies from place to place and region to region. Some local types are also under cultivation since long time. Further, some new varieties from State Agriculture Universities, National Institutes and Centers were also released during the recent past.

\section{Materials and Methods}

The present experiment was undertaken in the field of Chili and Vegetable Research Unit, Dr. Panjabrao Deshmukh Krishi Vidyapeeth, Akola in a Randomized Block Design (RBD) with seven treatment and three replications. The treatments include seven varieties $\mathrm{V}_{1}$ PusaDesi, $\quad \mathrm{V}_{2}$-PusaChetki, $\mathrm{V}_{3}$-PusaReshmi, $\mathrm{V}_{4^{-}}$PusaHimani, $\mathrm{V}_{5^{-}}$Japanese White, $\mathrm{V}_{6^{-}}$ ArkaNishant and $\mathrm{V}_{7^{-}}$IHR-1-1.

The soil of the experimental block was medium black. The field was prepended by ploughing and frequent harrowing. FYM was given at the rate of 25 cart load hectare ${ }^{-1}$ before last harrowing and mixed well with soil. The ridges and furrow was opened in a bed size $3.60 \times 2.30 \mathrm{~m}^{2}$. A spacing of $30 \mathrm{~cm}$ was kept between the ridges and seed was dibbled at $10 \mathrm{~cm}$ spacing. Fertilizer was done as per recommendation and all the necessary cultural practices were adopted. The observations on length of root, its diameter, and weight of plant and yield were recorded. The analyses of variance were carried out as suggested by Panse and Sukhateme (1957).

\section{Results and Discussion}

\section{Growth parameters}

\section{Plant height (cm)}

At 20 Days after Sowing, the radish plant attended maximum $24.40 \mathrm{~cm}$ of plant height in variety ArkaNishant, which was found at par with the varieties I H R-1-1 which was 20.26 $\mathrm{cm}$. The remaining varieties were at par with each other. However, the minimum plant height $16.42 \mathrm{~cm}$ was recorded in variety PusaHimani (Table 1).

At 40 Days after Sowing, the maximum plant height was recorded $25.96 \mathrm{~cm}$ in ArkaNishant, which was found at par with the varieties PusaChetki with height of $25.78 \mathrm{~cm}$ and Japanese White with $24.38 \mathrm{~cm}$. The remaining varieties PusaHimani, PusaReshmi, and I H R1-1 were at par with each other. Whereas, the minimum plant height was recorded $21.69 \mathrm{~cm}$ in variety PusaDesi (Table 1).

At harvesting stage, the maximum plant height $28.29 \mathrm{~cm}$ was attained by the variety ArkaNishant, which was found at par with the varieties Japanese White with $26.02 \mathrm{~cm}$ and PusaChetki with $26.28 \mathrm{~cm}$. The remaining varieties PusaDesi, PusaHimani and I H R-1-1 were at par with each other. However, the minimum plant height $23.50 \mathrm{~cm}$ was recorded in the variety PusaReshmi (Table 1). The plant height of different radish varieties was found to be significant at all the stages of observation. The maximum plant height 24.40 , 25.96, 28.29 cm was produced by ArkaNishant variety. These differences in plant height among the varieties might be due to the genetic makeup of the plant and its expression to the growing soil and environmental conditions. The variation in plant growth of different radish varieties were also observed, which confirms the results of present investigation Anjanappa et al., (1998). 


\section{Number of leaves plant $^{-1}$}

The number of leaves plant ${ }^{-1}$ at 20 Days after Sowing, were observed in different radish varieties. Significantly the maximum number of leaves 6.06 was noted in the variety Japanese White, which was found at par with the varieties PusaDesi, PusaHimani, PusaReshmi, ArkaNishant and IHR-1-1. Whereas, the minimum number of leaves plant $^{-1}$ was recorded 3.66 in variety PusaChetki (Table 2). At 40 Days after Sowing, the maximum number of leaves plant $^{-1} 8.20$ was produced by the variety I H $\mathrm{R}-1-1$. This variety was significantly found to be at par with the varieties PusaDesi, PusaHimani, PusaReshmi, ArkaNishant and Japanese White while the minimum number of leaves plant ${ }^{-1} 6.53$ was recorded in variety PusaChetki. At harvest, the maximum (12.33) number of leaves plant ${ }^{-1} 12.33$ were produced in Japanese White and it was at par with PusaReshmi, I H R -1-1. The remaining varieties PusaDesi, PusaHimani and ArkaNishant were at par with each other. Whereas, the minimum number of leaves plant $^{-1} 9.86$ were observed in variety PusaChetki (Table 2).

The significant difference in early stages of growth is obvious, as during germination and growth initiation process, the varieties might not have expressed their genetic potential. The significant differences thereafter could be attributed to the requirement of developing plants for more quantum of carbohydrates, which might have forced the plants of these varieties to produce more number of leaves. The variation in number of leaves among different radish varieties was also reported by Dixit et al., (1980), Ponnuswami et al., (1980), Kumar et al., (1995), Anjanappa et al., (1998), Rabbaniet al., (1998), Singh and Taj (2005), Chapagain et al., (2010) and Kumar et al., (2012), which supports the results of present findings.

\section{Leaf area $\left(\mathrm{cm}^{2}\right)$}

The data of leaf area indicated that, at 20 Days after Sowing the maximum leaf area 63.60 $\mathrm{cm}^{2}$ was recorded in ArkaNishant. The varieties PusaDesi, PusaHimani, PusaReshmi, PusaChetki, and Japanese White were at par with each other. However, the minimum leaf area $25.98 \mathrm{~cm}^{2}$ was recorded in I H R-1-1. At 40 Days After Sowing, the maximum leaf area $108.62 \mathrm{~cm}^{2}$ was recorded in variety ArkaNishant, which was at par with variety PusaChetki with $101.31 \mathrm{~cm}^{2}$, whereas, varieties PusaDesi, PusaHimani and PusaReshmi were at par with each other(Table 3 ). However, significantly the minimum leaf area $51.31 \mathrm{~cm}^{2}$ was recorded in I H R-1-1. At harvest, the maximum leaf area $120.92 \mathrm{~cm}^{2}$ was recorded in variety ArkaNishant, which was found to be at par with the varieties Japanese White with $117.83 \mathrm{~cm}^{2}$, I H R-1-1 with $113.40 \mathrm{~cm}^{2}$ and it was followed by the variety PusaChetki with $110.04 \mathrm{~cm}^{2}$ (Table 3). The varieties PusaDesi, PusaReshmi were at par with each other. The minimum leaf area $85.04 \mathrm{~cm}^{2}$ was recorded by the variety PusaHimani. These variations in leaf area among various varieties of radish might be attributed to their inherent characters. Maximum leaf area might be helpful for more photosynthesis and making food for better yield potential character of plant growth and produce maximum yield. Further, the growth characters of the plants greatly depend on the genetic makeup of the variety. Similar results were obtained by Singh and Taj (2005), Mapari et al., (2009) in radish crop.

\section{Chlorophyll content of leaves ( $\mathrm{mg} \mathrm{g}^{-\mathbf{1}}$ )}

The data presented in Table 4, indicate that, the difference in chlorophyll content of leaves of different varieties were found to be significant at all the growth stages. At 20 Days after Sowing, the maximum chlorophyll content of leaves $0.96 \mathrm{mg} \mathrm{g}^{-1}$ was observed in 
variety ArkaNishant and followed by Japanese White with $0.86 \mathrm{mg} \mathrm{g}^{-1}$. While, the minimum chlorophyll content $0.30 \mathrm{mg} \mathrm{g}^{-1}$ observed in I $\mathrm{H}$ R-1-1. At 40 Days after Sowing, significantly the maximum chlorophyll content of leaves $1.37 \mathrm{mg} \mathrm{g}^{-1}$ was recorded in variety ArkaNishant, which was at par with Japanese White's result with $1.23 \mathrm{mg} \mathrm{g}^{-1}$. However, the minimum chlorophyll content of leaves $0.82 \mathrm{mg} \mathrm{g}^{-1}$ was recorded in variety $\mathrm{I} \mathrm{H}$ R-1-1.

At harvest, the variety ArkaNishant recorded significantly the maximum chlorophyll content of leaves $3.10 \mathrm{mg} \mathrm{g}^{-1}$, which was at par with PusaHimani, PusaReshmi, PusaChetki, Japanese White, I H R -1-1. However, the minimum chlorophyll content of leaves $1.61 \mathrm{mg} \mathrm{g}^{-1}$ was recorded in variety PusaDesi. Significantly the maximum chlorophyll content of leaves was observed in variety ArkaNishant. The lowest chlorophyll content of leaves was obtained in variety PusaDesi and I H R-1-1. Chlorophyll content of leaves was might be varied according to leaf area and types of leaves and genotypic character. Similar results has been reported by
Mapari et al., (2009) in PusaChetki cultivar of radish.

\section{Yield Parameters}

\section{Length of $\operatorname{root}(\mathrm{cm})$}

The significant differences were observed in root length of different radish varieties. The maximum length of root $28.55 \mathrm{~cm}$ was obtained in variety Japanese White, which was at par with PusaHimani was with $26.98 \mathrm{~cm}$. However, the minimum length of root 19.94 $\mathrm{cm}$ was recorded in PusaDesi (Table 5). The remaining varieties PusaReshmi, ArkaNishant, I H R-1-1 were statistically at par with each other. The root length of a cultivar is the factor which is of main concern to the research. Medium long root is an important character regarding root quality and it is useful to classify the varieties for consumer acceptability which might be due to genetical diversity in different varieties and ecological condition. Similar results were obtained by Pujari et al., (1977), Gupta et al., (1974), Shridhar (1998) and Deotale et al., (1994) in radish crop.

Table.1 Performance of different radish varieties in respect of plant height $(\mathrm{cm})$

\begin{tabular}{|l|c|c|c|}
\hline $\begin{array}{l}\text { Treatment } \\
\text { (Varieties) }\end{array}$ & \multicolumn{3}{|c|}{ Plant height (cm) } \\
\hline V1 - PusaDesi & 18.10 & 21.69 & 23.95 \\
\hline V2 - PusaHimani & 16.42 & 23.28 & 23.70 \\
\hline V3 - PusaReshmi & 18.31 & 22.56 & 23.50 \\
\hline V4 - PusaChetki & 19.56 & 25.78 & 26.28 \\
\hline V5 - ArkaNishant & 24.40 & 25.96 & 28.29 \\
\hline V6 - Japanese White & 18.54 & 24.38 & 26.02 \\
\hline V7 - I H R-1-1 & 20.26 & 23.79 & 24.88 \\
\hline "F" test & Sig. & Sig. & Sig. \\
\hline SEm \pm & 1.40 & 0.62 & 1.02 \\
\hline CD at 5 \% & 4.33 & 1.91 & 3.15 \\
\hline
\end{tabular}


Table.2 Performance of different radish varieties in respect of plant height $(\mathrm{cm})$

\begin{tabular}{|l|}
\hline $\begin{array}{l}\text { Treatment } \\
\text { (Varieties) }\end{array}$ \\
\hline V1 - PusaDesi \\
\hline V2 - PusaHimani \\
\hline V3 - PusaReshmi \\
\hline V4 - PusaChetki \\
\hline V5 - ArkaNishant \\
\hline V6 - Japanese White \\
\hline V7 - I H R -1-1 \\
\hline "F" test \\
\hline SEm \pm \\
\hline CD at $5 \%$ \\
\hline
\end{tabular}

\begin{tabular}{|c|c|c|}
\hline \multicolumn{3}{|c|}{ Number of leaves per plant } \\
\hline 20 Days after Sowing & 40 Days after Sowing & At harvest \\
\hline 5.86 & 8.10 & 10.46 \\
\hline 5.40 & 7.80 & 11.33 \\
\hline 5.30 & 8.06 & 11.66 \\
\hline 3.66 & 6.53 & 9.86 \\
\hline 5.96 & 8.00 & 10.26 \\
\hline 6.06 & 8.00 & 12.33 \\
\hline 5.60 & 8.20 & 11.86 \\
\hline Sig. & Sig. & Sig. \\
\hline 0.43 & 0.31 & 0.29 \\
\hline 1.33 & 0.95 & 0.90 \\
\hline
\end{tabular}

Table.3 Performance of different radish varieties in respect of leaf area $\left(\mathrm{cm}^{2}\right)$

\begin{tabular}{l|}
$\begin{array}{l}\text { Treatment } \\
\text { (Varieties) }\end{array}$ \\
\hline V1 - PusaDesi \\
\hline V2 - PusaHimani \\
\hline V3 - PusaReshmi \\
\hline V4 - PusaChetki \\
\hline V5 - ArkaNishant \\
\hline V6 - Japanese White \\
\hline V7 - I H R-1-1 \\
\hline "F" test \\
\hline SEm \pm \\
\hline CD at $5 \%$ \\
\hline
\end{tabular}

\begin{tabular}{|c|c|c|}
\hline \multicolumn{3}{|c|}{ Leaf area $\mathbf{c m}^{\mathbf{2}}$} \\
\hline 20 Days After Sowing & 40 Days After Sowing & At harvest \\
\hline 34.76 & 53.01 & 87.76 \\
\hline 32.36 & 54.39 & 85.04 \\
\hline 28.14 & 61.84 & 95.46 \\
\hline 44.80 & 101.31 & 110.04 \\
\hline 63.60 & 108.62 & 120.92 \\
\hline 46.99 & 94.81 & 117.83 \\
\hline 25.98 & 51.31 & 113.40 \\
\hline Sig. & Sig. & Sig. \\
\hline 2.48 & 4.18 & 2.53 \\
\hline 7.64 & 12.88 & 7.82 \\
\hline
\end{tabular}

Table.4 Performance of different radish varieties in respect of chlorophyll content of leaves $\left(\mathrm{mg} \mathrm{g}^{-1}\right)$

\begin{tabular}{|l|}
\hline $\begin{array}{l}\text { Treatment } \\
\text { (Varieties) }\end{array}$ \\
\hline V1 - PusaDesi \\
\hline V2 - PusaHimani \\
\hline V3 - PusaReshmi \\
\hline V4 - PusaChetki \\
\hline V5 - ArkaNishant \\
\hline V6 - Japanese White \\
\hline V7 - I H R-1-1 \\
\hline "F" test \\
\hline SEm \pm \\
\hline CD at $5 \%$ \\
\hline
\end{tabular}

\begin{tabular}{|c|c|c|}
\hline \multicolumn{3}{|c|}{ Chlorophyll content of leaves $\left(\mathbf{m g ~ g}^{\mathbf{- 1}}\right)$} \\
\hline 20 Days After Sowing & 40 Days After Sowing & At harvest \\
\hline 0.50 & 0.94 & 1.61 \\
\hline 0.38 & 0.89 & 2.95 \\
\hline 0.42 & 0.94 & 3.04 \\
\hline 0.68 & 0.86 & 2.95 \\
\hline 0.96 & 1.37 & 3.10 \\
\hline 0.86 & 1.23 & 2.93 \\
\hline 0.30 & 0.82 & 2.74 \\
\hline Sig. & Sig. & Sig. \\
\hline 0.06 & 0.09 & 0.16 \\
\hline 0.19 & 0.30 & 0.49 \\
\hline
\end{tabular}


Table.5 Performance of different radish varieties in respect of length of root $(\mathrm{cm})$

\begin{tabular}{|l|}
\hline Treatment (Varieties) \\
\hline V1 - PusaDesi \\
\hline V2 - PusaHimani \\
\hline V3 - PusaReshmi \\
\hline V4 - PusaChetki \\
\hline V5 - ArkaNishant \\
\hline V6 - Japanese White \\
\hline V7 - I H R-1-1 \\
\hline 'F' test \\
\hline SEm \pm \\
\hline CD at $5 \%$ \\
\hline
\end{tabular}

\begin{tabular}{|c|}
\hline Length of root $(\mathbf{c m})$ \\
\hline 19.94 \\
\hline 26.98 \\
\hline 24.06 \\
\hline 21.74 \\
\hline 25.12 \\
\hline 28.55 \\
\hline 24.89 \\
\hline Sig. \\
\hline 0.86 \\
\hline 2.67 \\
\hline
\end{tabular}

Table.6 Performance of different radish varieties in respect of diameter of root $(\mathrm{cm})$

\begin{tabular}{|l|l|}
\hline Treatment (Varieties) & Diameter of root $(\mathbf{c m})$ \\
\hline V1 - PusaDesi & 3.10 \\
\hline V2 - PusaHimani & 2.99 \\
\hline V3 - PusaReshmi & 2.91 \\
\hline V4 - PusaChetki & 3.20 \\
\hline V5 - ArkaNishant & 3.69 \\
\hline V6 - Japanese White & 3.14 \\
\hline V7 - I H R-1-1 & 2.60 \\
\hline "F" test & Sig. \\
\hline SEm \pm & 0.17 \\
\hline CD at 5 \% & 0.52 \\
\hline
\end{tabular}

Table.7 Performance of different radish varieties in respect of total fresh weight of plant (g)

\begin{tabular}{|c|}
\hline Treatment (Varieties) \\
\hline V1 - PusaDesi \\
\hline V2 - PusaHimani \\
\hline V3 - PusaReshmi \\
\hline V4 - PusaChetki \\
\hline V5 - ArkaNishant \\
\hline V6 - Japanese White \\
\hline V7 - I H R-1-1 \\
\hline "F" test \\
\hline SEm \pm \\
\hline CD at $5 \%$ \\
\hline
\end{tabular}

\begin{tabular}{|c|}
\hline Total fresh weight of plant $(\mathbf{g})$ \\
\hline 190.06 \\
\hline 204.22 \\
\hline 214.74 \\
218.10 \\
226.60 \\
\hline 223.75 \\
216.10 \\
\hline Sig. \\
4.40 \\
\hline 13.58 \\
\hline
\end{tabular}


Table.8 Performance of different radish varieties in respect of root yield plot $^{-1}\left(\mathrm{~kg} \mathrm{plot}^{-1}\right)$

\begin{tabular}{|l|}
\multicolumn{1}{|c|}{ Treatment (Varieties) } \\
\hline V1 - PusaDesi \\
\hline V2 - PusaHimani \\
\hline V3 - PusaReshmi \\
\hline V4 - PusaChetki \\
\hline V5 - ArkaNishant \\
\hline V6 - Japanese White \\
\hline V7 - I H R -1-1 \\
\hline 'F' test \\
\hline SEm \pm \\
\hline CD at $5 \%$ \\
\hline
\end{tabular}

\begin{tabular}{|c|}
\hline Root yield plot \\
\hline \\
\hline 24.54 \\
\hline 26.73 \\
\hline 28.17 \\
30.32 \\
\hline 32.34 \\
\hline 30.67 \\
\hline 26.69 \\
\hline Sig. \\
\hline 0.25 \\
\hline 0.77 \\
\hline
\end{tabular}

Table.9 Performance of different radish varieties in respect of moisture content of root (\%)

\begin{tabular}{|c|c|}
\hline Treatment (Varieties) & Moisture content of root (\%) \\
\hline V1 - PusaDesi & $95.38(9.76)$ \\
\hline V2 - PusaHimani & $96.10(9.80)$ \\
\hline V3 - PusaReshmi & $97.23(9.85)$ \\
\hline V4 - PusaChetki & $96.58(9.82)$ \\
\hline V5 - ArkaNishant & $97.75(9.88)$ \\
\hline V6 - Japanese White & $97.15(9.85)$ \\
\hline V7 - I H R-1-1 & $95.35(9.76)$ \\
\hline \hline “F” test & Sig. \\
\hline SEm \pm & 0.47 \\
\hline CD at 5 \% & 1.43 \\
\hline (Figures in parenthesis indicates square root transformation).
\end{tabular}

Table.10 Performance of different radish varieties in respect of crude fiber content of root (\%)

\begin{tabular}{|c|c|}
\hline Treatment (Varieties) & Crude fiber content of root (\%) \\
\hline V1 - PusaDesi & $1.53(1.23)$ \\
\hline V2 - PusaHimani & $1.45(1.20)$ \\
\hline V3 - PusaReshmi & $1.57(1.25)$ \\
\hline V4 - PusaChetki & $1.33(1.15)$ \\
\hline V5 - ArkaNishant & $1.32(1.15)$ \\
\hline V6 - Japanese White & $1.39(1.18)$ \\
\hline V7 - I H R-1-1 & $1.71(1.31)$ \\
\hline "F" test & Sig. \\
\hline SEm \pm & 0.05 \\
\hline CD at 5 \% & 0.18 \\
\hline (Figures in parenthesis indicates square root transformation). \\
\hline
\end{tabular}




\section{Diameter of root $(\mathbf{c m})$}

The maximum root diameter $3.69 \mathrm{~cm}$ was recorded in variety ArkaNishant, which was at par with variety PusaChetki, while the minimum diameter of root $2.60 \mathrm{~cm}$ was recorded in variety I H R-1-1. The remaining varieties PusaDesi, Japanese White, PusaReshmi, PusaHimani were statistically at par with each other (Table 6). The diameter of root was significantly influenced among the different varieties. The root diameter affects to root yield when increase the diameter of root. The similar variations in diameter of root among different radish varieties have reported by Gupta et al., (1974).

\section{Total fresh weight of plant (g)}

The variety ArkaNishant recorded highest total fresh weight of plant $226.60 \mathrm{~g}$ which was statistically at par with variety Japanese White which was 223.75 g, PusaReshmi, PusaChetki, Japanese White, I H R -1-1. While, the minimum total fresh weight of plant was $190.06 \mathrm{~g}$ recorded in variety PusaDesi (Table 7). The variations in total fresh weight of plant among different radish varieties might be due to the varietal difference. The results of the present investigation are similar to that of Mapari et al., (2009) and Deotale et al., (1994) in radish.

\section{Root yield plot $^{-1}(\mathrm{~kg})$}

The data with respect of root yield plot $^{-1}(\mathrm{~kg})$ indicated that, the root yield plot $^{-1}$ was expressively inclined due to different varieties under study. The maximum root yield 32.34 $\mathrm{kg} \mathrm{plot}^{-1}$ was recorded in variety ArkaNishant which was followed by varieties Japanese White $30.67 \mathrm{~kg} \mathrm{plot}^{-1}$ and PusaChetki 30.32 $\mathrm{kg} \mathrm{plot}^{-1}$. The minimum root yield was 24.54 kg plot $^{-1}$ recorded in variety PusaDesi (Table 8 ). The root yield is a result of translocation of more quantum of carbohydrates from the source to the sink. As the varieties which have shown superior performance in yield have significantly more number of vigorous leaves on it and more plant height, which could have synthesized more food material and supplied to the roots, that might have resulted in increasing the weight and diameter of roots and ultimately resulted in getting higher root yield in these varieties. Contrarily, the minimum yield in variety PusaDesi could be attributed to poor growth in terms of low chlorophyll content of leaves and minimum leaf area leads to the production of less quantity of carbohydrates and ultimately the poor yield. These results are inconformity with finding of Singh and Taj (2005), Deotale et al., (1994) in radish.

\section{Qualitative parameters}

\section{Moisture content of root (\%)}

The variety ArkaNishant recorded supreme moisture content of root $97.75 \%$, which was statistically followed by the varieties PusaReshmi (97.23\%), Japanese White $(97.15 \%)$. Whereas, the varieties by each other PusaChetki (96.58\%) and PusaHimani $(96.10 \%)$ were found at par with each other.

The minimum $(95.35 \%)$ moisture content of root was recorded in variety I H R-1-1 (Table 9). The moisture content of root was significantly influenced among the different radish varieties under study. The variation in the moisture content of root might be due to the differences in the variation in the shape of root in general and length and diameter of it in particular. More the mass of root, maximum would be the moisture content in it. Ultimately, it varies as a varietal character in the crop like radish. The perusal of available literature does not show any evidence on the present aspect of the study. However, Bawkar (2011) recorded similar trends in carrot. 


\section{Crude fiber content of root $(\%)$}

The data showed that, significantly the minimum $1.32 \%$ of crude fiber content of root was recorded in ArkaNishant and followed by PusaChetki of $1.33 \%$ and Japanese White with $1.39 \%$. While, the variety I H R-1-1 recorded maximum of $1.71 \%$ crude fiber content of root. The lowest $1.32 \%$ of crude fiber content of root good quality indicated that radish variety of ArkaNishant while maximum crude fiber content in radish variety decreases quality and presence of pithiness in root give less market value 1.71 $\%$ in variety I H R-1-1 (Table 10). The minimum crude fiber percent was observed in variety ArkaNishant. This might be due to the genetic makeup of particular variety and probably could be the result of favorable agro climatic conditions available during the growth period. Similer results were reported by Kopta and Pokluda (2013) in radish crop.

The critical evaluation of the results of the present investigation indicated that, the radish varieties ArkaNishant, Japanese White and PusaChetki had shown the significantly superior performance with respect to most of the growth, yield and quality attributes. Hence, these varieties are suitable for agroclimatic conditions of Akola. Among seven varieties, the variety ArkaNishant performed better. Hence this genotype can be involved in further breeding programme for improving the yield and quality of radish.

\section{References}

Anjanappa, M., N. Shiva Reddy, K. Murli and K.S. Krishnappa, 1998. Performance of certain radish varieties under southern dry region of Karnataka. Karnataka $J$. Agric. Sci., 11(3), 862-864.

Bawkar, S.O. 2011. Effect of spacing and seed soaking with GA3 on growth, yield and quality of carrot. M.Sc. (Horti.) thesis submitted to Dr. P.D.K.V, Akola (unpublished).

Chapagain, T. R., S. Piya, N. B. Dangal, J. L. Mandal, and B. P. Chaudhary, 2010. Comparisons of commercial and local varieties of radish at different level of manures and fertilizers. Nepal J. Sci. Tech. 11, 51-56.

Deotale, A.B., P.V. Bilorkar, N.G. Bedvaik, S. R. Patil, and J. R. Rathod, 1994. Studies on performance of some radish (Raphanus sativus L.) cultivars under Nagpur condition. J. Soils and Crops 4(2), 120-121.

Dixit, J., R. P. Singh and G. S. Gaur, 1980. A note on studies on varietal performance of radish (Raphanus sativus L.). Haryana J. Hort. Sci. 9(1-2), 98-100.

Gautam, I. P. and P. P. Khatiwada, 1997. Results on purification of Bhetedar Local radish. Working paper no. 205 Phakirbas Agriculture Center, Dhankuta, Nepal. Pp. 1- 6.

Gupta, P.K., K.G. Mahakal and K.T. Sadawarte, 1974. Promising varieties of radish (Raphanus sativus L.) The PKV Res. J. 2, 139-140.

Kirtikar, K. R. and B. D. Basu, 1935. Indian Medicinal Plants. Lalit Mohan Basu, Allahabad.

Kopta, T., and R. Pokluda, 2013. Yields, quality and nutritional parameters of radish (Raphanus sativus) cultivars when grown organically in the Czech Republic. Hort. Sci. (Prague), 40, 1621.

Kumar, J.C., B.S. Sooch, and D.S. Khurana, 1995. Studies on evaluation of radish cultivars for yield and its parameters during spring season. The Punjab Veg. Grower. (30), 62-63.

Kumar, R., R. Sharma, R.K. Gupta, and M. Singh, 2012. Determination of genetic variability and divergence for root yield and quality characters in temperate 
radishes. Int. J. Veg. Sci. 18(4), 307318.

Mapari, A.V., V.N. Dod, P.D. Peshattiwar and ArchanaThorat, 2009. Genetic variability in radish. The Asian J. Hort. 4 (2), 225-258.

National Horticulture Board, 2012. Govt. of India. National Data base www.nhb.gov.in.

Panse, V. G. and P. U. Sukhatme, 1957. Statistical methods for agricultural workers, Indian Council of Agriculture Research publication New Delhi.

Ponnuswami, V., E. Vadivel, and I. Irulappan, 1980: Studies on variability studies in Radish (Raphanus sativus L.). South Ind.Hort. 30, 42-44.
Rabbani, M.A., Y. Murakami, Y. Kuginuki, and K. Takayanagi, 1998. Genetic variation in radish (Raphanus sativus L.) germplasm from Pakistan using morphological traits and RAPDs. Genetic Resources and Crop Evaluation ,(45), 307-316.

Salaria, A. S.and B. S. Salaria, 2009. Horticulture at a Glance. Jain Brothers, New Delhi 2: 7- 8.

Singh, V.B. and R.K. Taj, 2005: Evaluation of radish cultivars under rain fed conditions of Nagaland. Prog. Horti. 37 (1): $72-74$.

Thamburaj, S. and Singh N. 2005. Vegetables, Tuber Crops and Spices. New Delhi: Indian council of Agriculture Research. pp 40.

\section{How to cite this article:}

Dongarwar, L.N., Sumedh R. Kashiwar, S.M. Ghawade and Usha R. Dongarwar. 2018. Varietal Performance of Radish (Raphanus sativus L.) Varieties in Black Soils of VidharbhaMaharashtra, India. Int.J.Curr.Microbiol.App.Sci. 7(01): 491-501. doi: https://doi.org/10.20546/ijcmas.2018.701.058 